\title{
TAXONOMIC VALUE OF ANTENNAL SEGMENTS OF CERTAIN COCCIDAE.
}

\section{A. H. Hollinger, Missouri Agricultural Experiment Station.}

During the past two seasons the writer has been making special investigation of the Coccidce of Missouri, and during that time many interesting forms, Diaspince as well as others, have been found, including several new and rare species. The Diaspince, while presenting certain problems in themselves,are not nearly so perplexing as are the mealy bugs, including Phenacoccus, Pseudococcus, and Trionymus, the Eriococcids, the Lecania, and other genera of the Coccince. While it is a comparatively simple matter to identify armored scale insects by means of the pygidia, it has been an almost impossible task for the average entomologist to separate the different species of the so-called soft scales, due to the fact that there have been very few constant, tangible characters for comparison in this broad group. Some writers have made a study of the fringe of setæ and accompanying gland pores surrounding the anal openings in certain of the mealy bugs (5). Others have studied the cerarii (5) which are the grouped conical spines and accompanying gland pores along the sides of certain of the mealy bugs. A few have elaborated on the structures of the anal plates of the Lecania (2). Many others have attempted to characterize species of Coccida by establishing a formula for the lengths of the antennal segments. While each of these may be of some value in strict systematic work, the practicability of using any one of these for easy identification of species is slight, at best. What is needed in coccidology is to put the study of soft scales upon a practical working basis, and so it was with this aim in view that the writer has given much of his time to close inspection and careful comparative study of the several genera of the native soft scale insects.

Cockerell's note (4), in which mention was made concerning the value of antennal segments in the determination of coccid species when antennal curves were plotted, led the writer to investigate this method.

There has been much debate among entomologists as to whether or not antennæ in coccids are of any taxonomic value. 
Marlatt (1) stated that he had the gravest doubts as to the value of the measurements of antennal segments in the determination of species, because the antennal formulæ varied so greatly even in the same individual. Pergande (1), Smith (3), and undoubtedly many others have been misled into thinking similarly because of the apparent discrepancies which arise in the antennal formulæ of any particular species, but which, if carefully worked out by the curve method, would present a definite working basis for that species. Quoting Cockerell (4): "It does not follow, as some uncritically assume, that antennal measurements are useless" just because the antennal formulæ are so variable.

Due to the fact that no published directions for making the curves were known to the writer at the time this investigation was started, he proceeded along lines of his own initiative and used a system for the graphic representation of the antennal segments which not only shows the general trend of the individual curves, but also shows the mean curve for all the measurements of normal antennæ in any particular species.

Using millimeter graph paper, the writer laid off in succession, working downward on the vertical axis or axis of ordinates, distances of ten millimeters. Each unit of ten millimeters was let represent one antennal segment. It is needless to mention that this unit was an arbitrary one, for the writer might just as well, except for lack of space, have taken larger units. On the horizontal axis, or axis of abscissis, the lengths of the successive antennal segments were plotted, one millimeter being used to represent a length of one micron. The writer could have taken a different unit, but for the sake of simplicity and compactness, the above-mentioned one was chosen. These units have been used in all the accompanying curves, and consequently they are uniform and comparative. Connecting the points in succession along the direction of the vertical axis produced the graphic figures. In all cases under observation, these curves are distinctive and characteristic of each species the writer has studied, as a comparison of the figures will show. All figures have been photographically reduced one-half.

After having followed this system for producing the antennal curves, the writer learned, through the United States Bureau of Entomology, that Brain (6) had published a few years previously the graphic representations of the antennal segments 
of certain South African species of Coccida. Reference to this paper, however, led the writer to adopt the plan of the curves as originally used, and not to adopt the method used by Brain. To the writer, as well as others who have inspected this paper, the curves shown herein are to be preferred over those of Brain's, for they give the general trend of the individual curves, the general trend of the curves of the species as a whole, and the mean curve of the species.

According to Cockerell (4): "the curves will of course vary, hardly any two antennæ being exactly alike; but except for abnormalities (pathological specimens), nearly every species gives quite different curves, while two species, very different in other respects, will give nearly the same curve. Some of the widely distributed species give curves almost too variable to be of much service, but in these cases, it is possible that the material contains more than one thing."

Brain (6) summarizes the taxonomic value of antennal segments of Coccide as follows: "The lengths of the antennal segments are of great importance in the determination of species if the measurements are accurately made from stained specimens and properly tabulated." "The most useful arrangement of antennal data seems to be arrived at by giving the range of variation in the measurements of the different segments, with the addition, perhaps, of the mode of each. After working over a large series of slides, one is impressed with the characteristic appearance of the different antennæ. But this difference is difficult to express. The nearest approach is obtained by a" graphic representation of the lengths of the antennal segments, "and this supplies a most useful aid for the preliminary location of an insect from slide specimens." "Similarity of antennal curves, while indicating similarity of antennal formulæ, does not of necessity indicate identity of species, but it does give a clue to work upon and possibly at times indicates relationships."

The writer is led to believe that these graphs are one of the main characterizing taxonomic features, and this view has been strengthened and sustained by several incidents and observations, among which the following will clearly illustrate their importance.

Several lots of Pseudococcids were collected by the writer, one of these in early spring of 1916 under the rough bark of 
wild grape, about ten miles south of Columbia, Missouri, and the others in and around Columbia, Missouri, during midsummer upon Lactuca canadensis, L. sagetifolia, Geum canadense and Solidago stricta. Careful mounting and examination of the materials on the above mentioned annuals and on the perennial Solidago stricta readily disclosed the fact that these four lots belonged to the same species, Pseudococcus shaferi species novo, and the antennal graphs further substantiated this result beyond a doubt. The material from wild grape was also mounted, there being one adult female and several nymphs. The antennal graph, as first made, was misleading, due to the fact that the antennal measurements of the adult and of the young were plotted together, thus hiding the true antennal graph of the adult. So this coccid on wild grape was at first referred by the writer in his manuscript to a new species. It was only after replotting the antennal measurements of the adult's segments that the similarity to the graph of Pseudococcus shaferi species novo was observed. Careful comparisons of the descriptions also showed identical details, such as the alveolated posterior coxa, the size of the leg segments, the anal ring and anal lobe setæ, the conical spines in the cerarii, the spiracles, the obscureness of the cerarii anterior to those on the anal lobes, etc., so that undoubtedly the coccid from wild grape is also Pseudococcus shaferi species novo. The reason for the apparent difference in food habit is that this coccid, feeding upon annuals and perennials throughout the growing season, forsakes such situations late in the fall and ascends to places which will insure dryness and protection throughout the winter and early spring and here forms its ovisac, the spring brood descending to feed upon the preferred food plants, which are either annual or perennial. Such procedure has been observed in the case of Trionymus americanus (Ckll.) which left its food plants-several kinds of grasses-and ascended the trunks of different species of trees late in the fall, and upon which their ovisacs were formed.

Other similar instances might also be cited, but the writer feels sure that the value of the graphic representations of the lengths of antennal segments has been clearly shown in the above cited case.

It will be noticed in the discussion of the accompanying graphs that the writer gives the antennal formula of the mean 
curve of each species. While these formulæ are not considered to be of primary importance, they at least remain fairly constant for each species where a large number of measurements have been plotted. Where it was possible to use only a few measurements, the formulæ of the mean curves of those species would probably vary to a slight extent if more measurements had been used. In all cases as many measurements as possible were plotted, ranging from only two or three to over sixty.

The writer does not merely characterize the various new species of coccids upon the basis of the antennal segments alone, but in all cases they formed the working basis for their identifications. One thing worthy of note is that all the species of $P$ seudococcus known to occur in Missouri have the last antennal segment the longest, as is shown by the antennal formulæ of the mean curves of those species, or by the mean curves themselves. On the other hand, most of the remaining species do not have the distal segment the longest.

The new species of scale insects mentioned in this paper are fully described, figured, and discussed by the writer in his manuscript on the Coccidæ of Missouri. They will later be published in a Missouri Agricultural Experiment Station bulletin, so that the exact distribution, food plants, and further distinguishing characters of these new species will be forthcoming in the near future.

\section{BIBLIOGRAPHY.}

(1) Marlatt, C. L. April, 1899. Remarks on Some Recent Work on Coccida; Proceedings of the Entomological Society of Washington; Vol. 4, pp. 383-389.

(2) Thro, Wм. C. 1903. The Genus Lecanium; Cornell Experiment Station Bulletin No. 209; plates 5; pp. 206-227.

(3) Smith, P. E. 1911. Some Specific Characters of the Genus Pseudococcus; Annals of the Entomological Society of America; Vol. 4, part 3; pp. 309-327; tables 15 .

(4) Cockerell, T. D. A. 1913. Phenacoccus betheli Again; Canadian Entomologist; Vol. 45, pp. 14-15.

(5) Sмiтн, P. E. 1913. Some Specific Characters of the Genus Pseudococcus; Journal of Entomology and Zoology; Vol. 5; part 2; pp. 69-84; tables 5; figures 17 .

(6) Brain, C. K. 1915. In Transactions of the Royal Society of South Africa; Vol. 5; part 2: pp. 65-194. 


\section{EXPLANATION OF PLATES}

\section{Plate XIX}

FIGURE 1 represents the antennal curves of a new species of Coccine, Exeretopus boonei species novo which has two segments to the tarsi. The writer places it in the genus Exceretopus (which may be the same thing as Luzulaspis) because of this peculiarity. It is the only one of this genus found in Missouri. Some of the other distinguishing characters are the whip-tail gland ducts, the marginal fringe of body setae or spines, the large Sclerotinia-shaped spiracles, the anal plates, the anal ring, etc. Ulmus americana is one of its hosts. The antennal formula for the mean curve is $4831(56) 72$.

Figure 2 is the antennal graph of Phenacoccus regnillohi species novo. This species is further characterized by the stout, white, waxy Orthezia-like lamellae, by the cerarical spines, by the deep maroon color of the body, by the spiracles, etc. Ostrya virginiana is the only known host. The antennal formula for the mean curve is $93251(678) 4$.

Figure 3 is the graph of Phenacoccus celtisifolice species novo, found feeding upon the leaves of Celtis occidentalis. Although this graph bears a slight resemblance to that of Figure 5, it may be readily separated from it by the presence of simple body glands, by the cerarii, by the absence of long, glassy, hair-like filaments, by the shape of the body and by the canary-yellow color of the body. The antennal formula for the mean curve is 239154678 .

FIGIRE 4 represents the antennal curves of Phenacoccus grandicarpos species novo. It is also characterized by the large size of the adult female, being the largest species of this genus the writer has seen; by the cerarii, and by the teagreen color which results when boiled in $10 \% \mathrm{KOH}$. The antennal formula for the mean curve is $92178(35) 64$.

Figurl: 5 is of Phenacoccus pettiti species novo, the most common species of this genus in Missouri. This species is further distinguished by bearing many long, waxy, glassy, hair-like filaments on the dorsum, by the grayish color of the body, by the cerarii, and by the peculiar body glands. The antennal formula for the mean curve of this species is 329541678 .

Figure 6 is the curve of Coccus hesperidum Linn. The antennal formula for the mean curve is 3472165 .

FIGI'RE 7 is the graph of Lecanium nigrofasciatum Perg. The antennal formula for the mean curve is 362154 . The over-wintering stage of this species was used for sturly.

Figrer 8 shows how the antennal segments of Saissetia olece (Bern.) appear when plotted. 'The antennal formula for the mean curve of this species is $32(18) 4567$.

\section{Plate XX}

FIGURE 9 is the graph of Eriococcus borealis Ckll. which the writer has found on Celtis occidentalis and Aesculus glabra. The first antennal segments are not plotted, because of the difficulty of obtaining exact measurements of the basal joints. The antennal formula for the mean curve of the adults is 342765 . Figure 11 is the graph of the antennae of the nymphs of this species. The antennal formula for the mean curve of the nymphs is 732465 .

FIG'RE 10 shows the curves of Coccus elongatus (Sign.). The antennal formula for the mean curve of this species is $3218(45) 67$.

FigURE 11. The legend for this is embodied in the discussion of Figure 9.

Figure 12 represents the curves of the common greenhouse mealy bug, Pseudococcks cilri (Risso). The antennal formula for the mean curve is 82317654 .

FroURE 13 is the graph of Lecaniodiaspis pruinosa Hunter. It is a common species in this part of the country. The antennal formula fot the mean curve is 435127689. The immature females with eight-segmented antennae should not be confused with the adlult females, although they appear similar externally. 
FIGURE 14 is the curve of Eriococcus missourii species novo. It is further characterized by the peculiar striped, dermal, color markings of the females. The antennal formula for the mean curve is 437256 . The first segment is not considered, because of the difficulty in measuring its length.

FIGURE 15 is the graph of a variation of Eriococcus missourii species novo. It apparently is a six segmented form, the third joint being the longest and about equal to segments Nos. 3 and 4 of the seven segmented form. The antennal formula for the mean curve of the six-segmented form is 36254 . The first antennal segments are not plotted.

Figure 16 is the curve of Pseudococcus nipa (Mask.) a very pretty, sedentary mealy bug. The antennal formula for the mean curve of this species is 72(13)6i4.

FIGURE 17 is the graph of Gossyparia spuria (Modecr) collected on elm in Michigan. It is not indigenous to Missouri so far as the writer knows. The antennal formula for the mean curve of this species is 342756 .

FIGURE 18 is the graph of Lecanium spp. non det. found in large numbers upon ash. The antennal formula for the mean curve is 3471265 .

FIGURE 19 shows the curves of another Lecanium, L. spp. non det. found abundantly upon elm. The antennal formula for the mean curve is 3472165 .

\section{Plate XXI}

Figure 20 represents the antennal segments of Pseudococcus shaferi species novo, found upon annuals and perennials, and also hibernating under the rough, exfoliating bark of wild grape. This particular curve was formerly thought, by the writer, to belong to a distinct species, but subsequent examination and comparison of the material with that which was used to produce the curves in the next figure, showed conclusively that it was the same species. No mean curve is shown in this figure, because that of Figure 21 applies to this, as well.

Figure 21 is the graph of Pseudococcus shaferi species novo. It is further characterized by the cerarii, etc. The antennal formula for the mean curve of the adults of this species is $82137(56) 4$. Figure 23 is the graph of the nymphs' antennae. The antennal formula for the mean curve of the antennae of the nymphs is 632154 .

Figure 22 is the graph of the antennal segments of Pseudococcus jessica Hollinger. Descriptions and figures of this species are given in the Canadian Entomologist for December, 1916, and for January, 1917. The antennal formula for the mean curve of this species is $8(12) 37564$.

Figure 23 (See legend as given under Figure 21).

Figure 24 is the graph of Pseudococcus morrisonii species novo, collected from white hickory. It is further characterized by the cerarii. The antennal formula for the mean curve of this species is 81237654 .

FIgURE 25 is the graph of Pseudococcus mcdanieli species novo. This species is further characterized by forming an ovisac of white, fluffy filaments which of ten completely cover the body of the adult female; also by the seven segmented antennae, by the cerarii, etc. Ragweed, Ambrosia trifida, seems to be its most preferred food plant. The antennal formula for the mean curve is $713(24) 65$.

FIGURE 26 is graph of the nymphal stage of Trionymus americanus (Ck11.). This species is a grass feeding coccid. The antennal formula for the mean curve of the nymphal antennae is 7126435 .

Figure 27 is the graph of the adults' antennae of the species, Trionymus americanus (Ck11.). This species is further characterized by having cerarical spines only on the ultimate and penultimate segments. The antennal formula for the mean curve of the adults' antennal measurements is 81273564 . 


\section{Plate XXII}

Figire 28 is the graph of Pseudococcus pseudonipa (Ckll.) collected from palms. The antennal formula for the mean curve of this species is 71246(35).

FIGLRE 29) is the graph of the clover-root mealy bug, Pseudococcus trifolii (Forbes). It is further characterized by the cerarii, which occur only on the ultimate segment of the winter female. The antennal formula for the mean curve of this specie's is 7126435 .

Figire 30 is the curve of the measurements of the antennal segments of Lecanium spp. non det. collected only from perennials. The antennal formula for the mean curve of this species is 3427165 .

Figire 31 is the graph of Pseudococcus omniverae species novo, which is very common and omniverous in its feeding habits. It is further characterized by the cerarii, lermal characters, ete. The antennal formula for the mean curve of this species is 83215764 .

Flaire 32 represents the curves of Pulinaria amygdali $\mathrm{Ck} 11$, found abundantly upon the leaves of gooseberry. The antennal formula for the mean curve is 32145867 .

FIGCRE: 33 is the graph of a seren segmented species of coceid found on sycamore, Lecanium sppr. non det. The antennal formula for the mean curve is $732(14) 65$.

FIG'RE 34 represents the golden rod Orthezia, O. solidaginis Sanders, a very common specie's around Columbia, Missouri. The antennal formula for the mean curve is $3815+6(27)$.

FIGire 35 shows the curves of Pseudococcus longispinus (Targ.). The antennal formula for the mean curve of this species is 82315467 .

Ficire 36 is the graph of Pulinaria ritis (Linn.) the cottony maple scale. The. antennal formula for the mean curve of this species is $34218 \tilde{j}(6 \overline{7})$. 


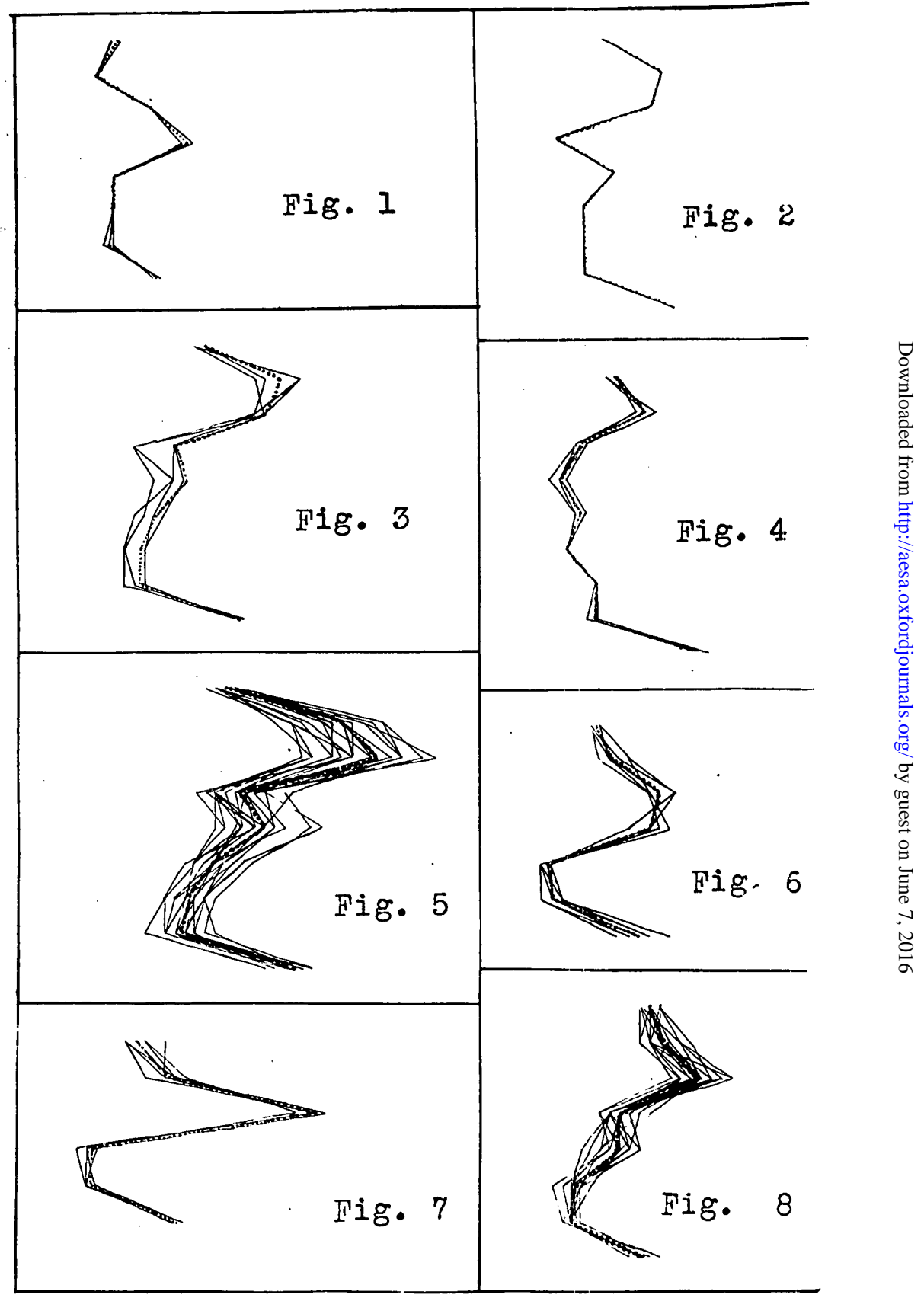

A. H. Hollinger. 


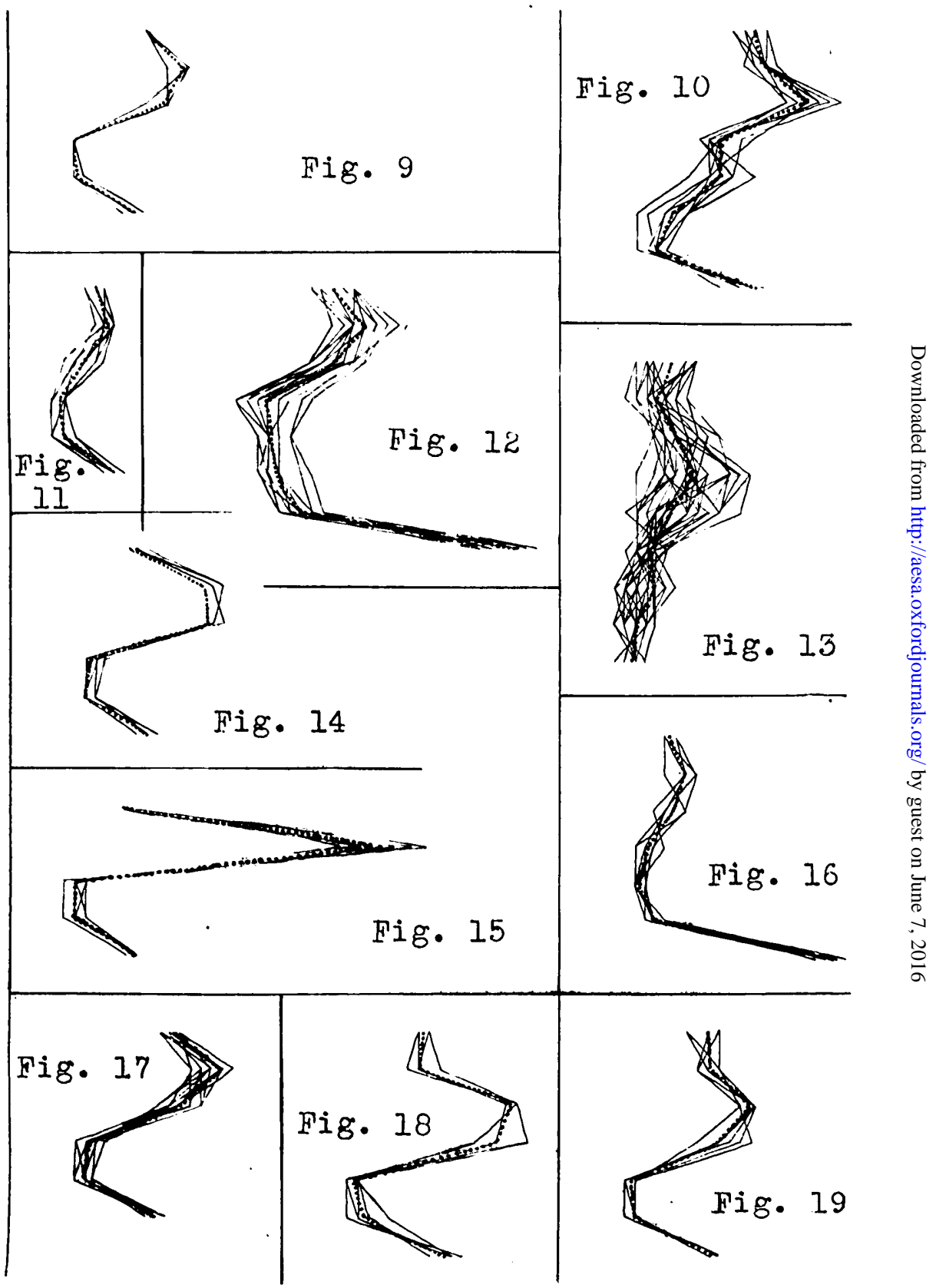


AnNals E. S. A.

Vol. X, Plate XXI.

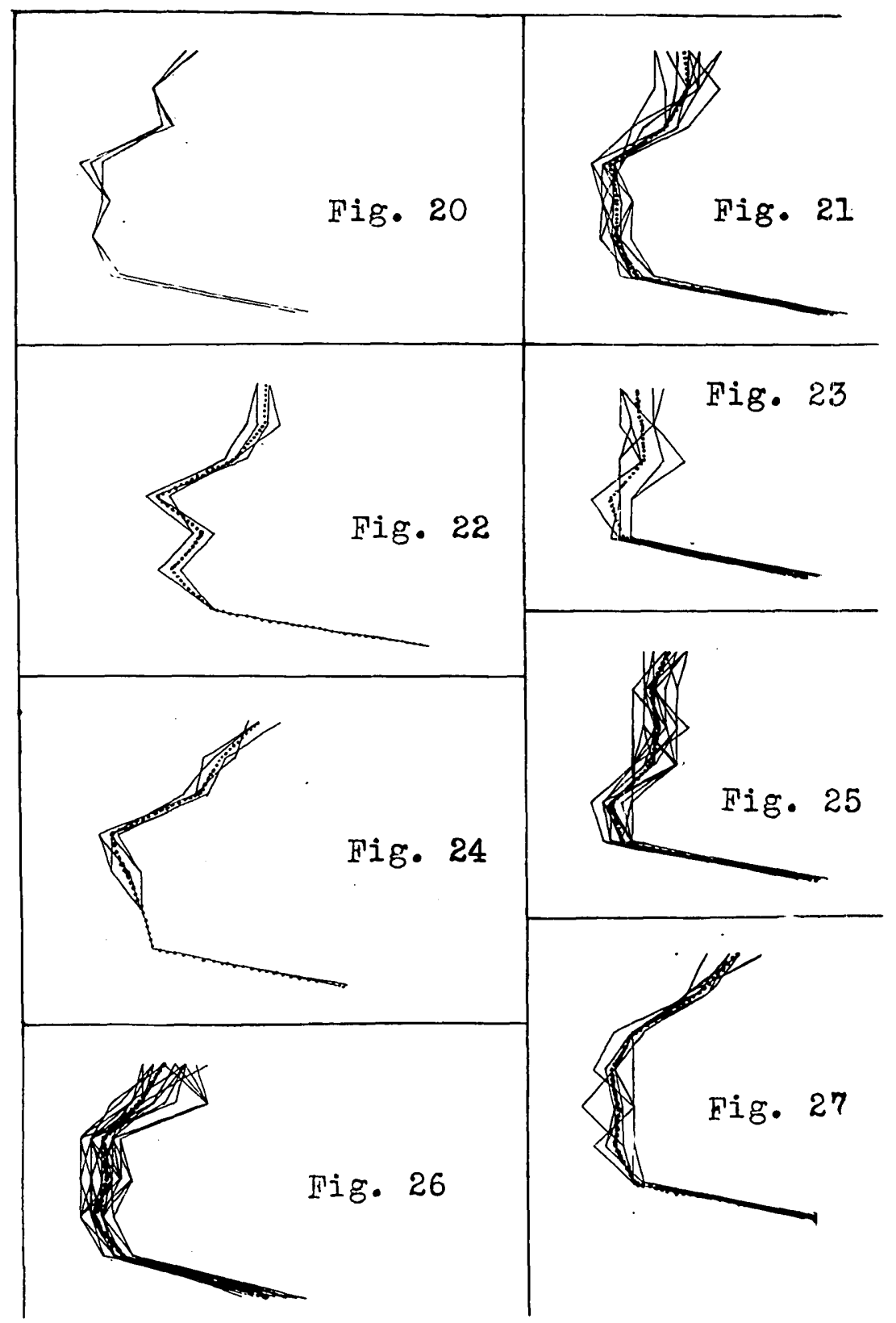

0
0
0
0
0
0
00
0
0
0
0
0
0
0
0
00
00
00
0
0
0
0
0
0
0
0
0
0
0
00
0
0
00
0
0
0
0
0
0
0
0
0
0
0
0

A. H. Hollinger. 
AnNals E. S. A.

Vol. X. Plate XXII.

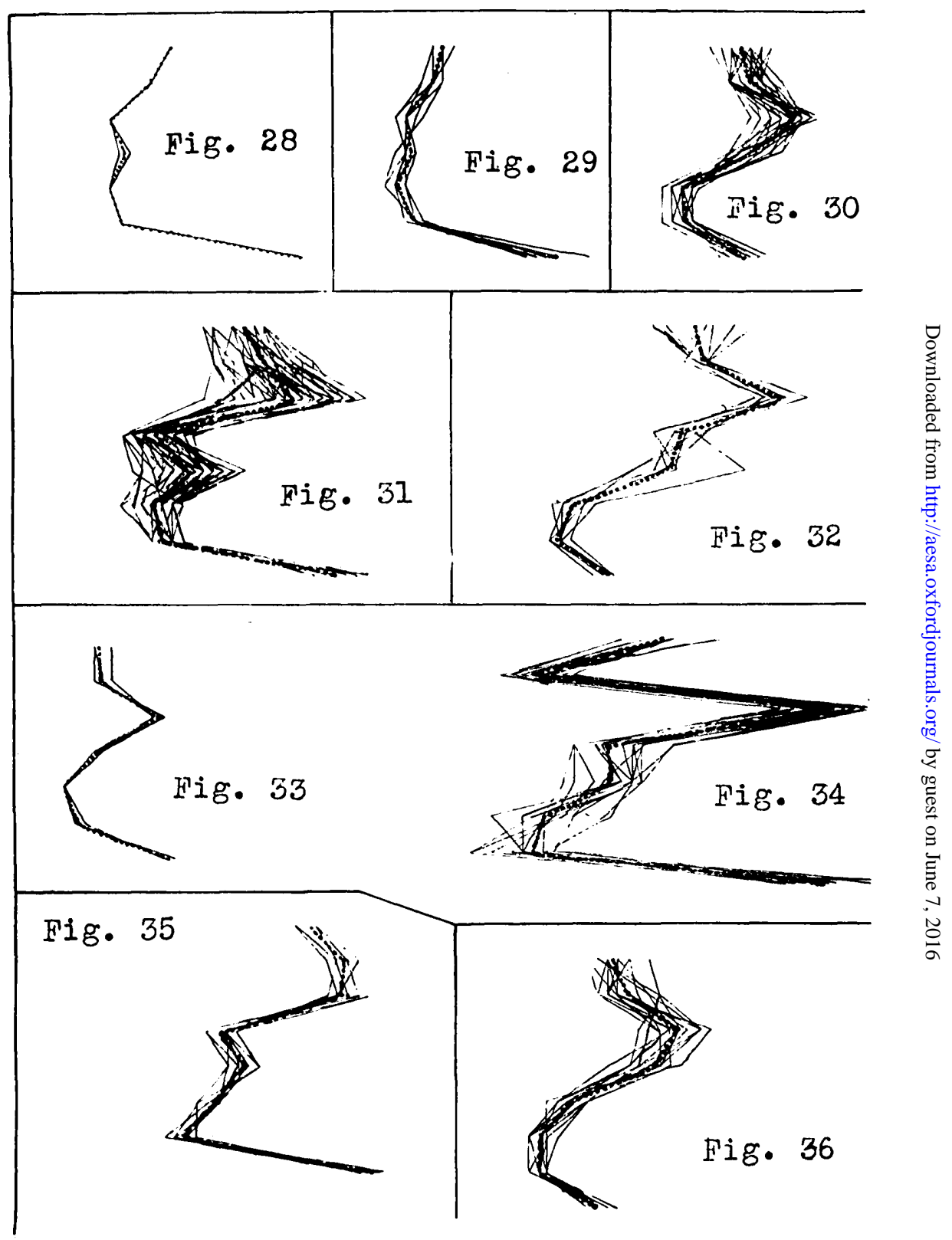

A. H. Hollinger. 